\title{
Apoyo a la investigación de accidentes aéreos con el uso de RPAs*
}

| Fecha de recibido: 5 de marzo del 2020 | Fecha de aprobación: 29 de abril del 2020 |

\section{Edgar Leonardo Gómez Gómez}

Magíster en Ingeniería de Telecomunicaciones

Docente de tiempo completo,

Universidad Distrital Francisco José de Caldas

Grupo de Investigación: GIDENUTAS

Rol de investigador: intelectual, comunicativo https://orcid.org/0000-0002-9544-0265

$\bowtie$ elgomezg@udistrital.edu.co

\section{Julio Enoc Parra Villamarín \\ Ingeniero Aeronáutico}

Docente de cátedra e investigador Independiente Grupo de Investigación: TESDA

Rol de investigador: intelectual, experimental https://orcid.org/0000-0003-1309-5128

$\bowtie$ julioenocparra@outlook.com

\section{Julieta Vélez Mejía}

Abogada, piloto comercial e investigadora Independiente

Grupo de Investigación: GINA

Rol de investigador: intelectual, experimental https://orcid.org/0000-0003-2208-5271

$\bowtie$ julietavelezm@gmail.com

* Artículo de investigación derivado del proyecto Implementación de RPAS en la escena de accidentes aéreos.

Cómo citar este artículo: Gómez Gómez, E. L., Parra Villamarín, J. E., Vélez Mejía, J. (2020). Apoyo a la investigación de accidentes aéreos con el uso de RPAS. Revista Ciencia y Poder Aéreo, 15(1), 24-38. https://doi.org/10.18667/cienciaypoderaereo.654 


\section{Apoyo a la investigación de accidentes aéreos con el uso de RPAS}

\section{Supporting the Investigation of Aircraft Accidents \\ Using RPAS}

\section{Apoio à pesquisa de acidentes aéreos com o uso de RPAS}

Resumen: Este documento presenta un estudio para la implementación de RPAS (por sus siglas en inglés, Remotely Piloted Aircraft System) en la investigación de un accidente aéreo. El propósito del estudio es evaluar la pertinencia de la implementación de dicha tecnología como herramienta válida y oportuna para el equipo de investigadores de accidentes aéreos. Para ello se realiza una revisión técnica de las capacidades generales de los RPAS y un análisis de Base Line. Este análisis se hace partiendo de una clasificación por peso, que remite a los datos de performance de cada aeronave, contenida en sus fichas técnicas de fábrica. Fueron analizados RPAS multirotor con sensores especializados para misiones específicas y también las regulaciones que permiten su implementación en la escena del accidente aéreo. Se comparan además, los procedimientos actuales con aquellos que incluirían la utilización de RPAS en dicha escena. Para finalizar, se presta especial atención a la tecnología, clase de aeronave, sensórica, modos de operación, tiempo y costos. Se concluye que la implementación de los RPAS facilitaría la obtención de imágenes y otros datos en el lugar de los hechos. Esta tecnología, que evoluciona exponencialmente, podría ser incluida como una de las herramientas en la labor de un investigador de accidentes.

Palabras clave: Accidentes aéreos; drones; investigación; procesamiento de imágenes; RPAS (Remotely Piloted Aircraft System); seguridad operacional.

Abstract: This paper presents a study for the implementation of Remotely Piloted Aircraft System (RPAS) in the investigation of an aircraft accident with the purpose of evaluating the relevance of this technology as a tool for Accident Investigation Groups (AIG) worldwide. A technical review of the general capabilities of the RPAS and a "baseline" analysis based on a weight classification approach is carried out, making reference to the data of each aircraft contained in their corresponding data sheet, which would facilitate obtaining images and other data at the scene. Multi-rotor RPAS with specialized sensors for specific missions as well as the regulations that require their implementation at the scene of the plane crash were studied. In addition, currently used procedures are compared with those that would include the use of RPAS at the scene. Finally, special attention is paid to technology, aircraft class, sensory, modes of operation, time, and costs, which allow concluding that the implementation of RPAS facilitates obtaining images and other data at the scene of accidents. This technology could be included as one of the tools that accident investigators must use in their work.

Keywords: Air Accidents; Drones; Investigation; Image Processing; RPAS (Remotely Piloted Aircraft System); Air Safety.

Resumo: Este documento apresenta um estudo para implementação de RPAS (Remotely Piloted Aircraft System) na investigação de um acidente de avião. O propósito do estudo é avaliar a relevância da implementação dessa tecnologia como uma ferramenta válida e oportuna para a equipe de investigadores de acidentes aéreos. Para isso, é realizada uma revisão técnica dos recursos gerais dos RPAS e uma análise de Base Line. Essa análise é feita baseada em uma classificação por peso, que faz referência aos dados de desempenho de cada aeronave, contidos em suas fichas técnicas de fábrica. Do mesmo modo, foram analisados RPAS multirotores com sensores especializados para missões específicas e os regulamentos que permitem seu uso no local de um acidente aéreo. Os procedimentos atuais também são comparados com os que incluíram o uso de RPAS neste cenário. Finalmente, é prestada atenção especial à tecnologia, ao tipo de aeronave, sensórica, modos de operação, tempo e custos. Por tanto, conclui-se que a implementação dos RPAS facilitaria a obtenção de imagens e outros dados no local. Esta tecnologia que está evoluindo exponencialmente, poderia ser incluída como uma das ferramentas no trabalho de um investigador de acidentes.

Palavras-chave: Acidentes aéreos; Drones; Investigação; Processamento de imagens; RPAS (Remotely Piloted Aircraft System); Segurança operacional. 


\section{Introducción}

Las condiciones del terreno de Colombia son muy especiales porque el país es atravesado de Sur a Norte por la cordillera de los Andes. Esta cordillera se divide en tres brazos y presenta tanto elevaciones de más de cinco mil metros sobre el nivel del mar como valles cercanos al nivel mar. Además, una vasta área del territorio colombiano está cubierta por la selva amazónica. El territorio ofrece una gran diversidad de patrones climáticos debido a la complejidad del terreno. La posición geográfica del país se encuentra en la región tropical ecuatorial, donde no hay estaciones meteorológicas; además, la ionosfera es más densa y dinámica que en otras latitudes (Bell, 2012).

Las condiciones mencionadas tienen una gran influencia en el tránsito aéreo, primordialmente debido a las concentraciones de población entre las cuales se mueve el transporte aéreo. Los principales aeropuertos y vías aéreas en Colombia están ubicados sobre las cordilleras de los Andes. La experiencia de los investigadores, comparada con la de entidades homologas de otros países miembros de la Organización de Aviación Civil Internacional (OACI, s.f.), refleja que una alta tasa de accidentes aéreos sucede en sitios remotos, de difícil acceso (Aerocivil, 2016). La investigación de los accidentes aéreos en Colombia enfrenta desafíos inusuales, en comparación con otras partes del mundo, debido a estas condiciones acceder a los lugares y tomar fotografías es una tarea difícil. El Grupo Colombiano de Investigación de Accidentes (AIG) ha dependido principalmente de helicópteros de la Fuerza Aérea (y, a veces, de helicópteros privados) para obtener imágenes aéreas. Estas imágenes han sido útiles, pero no son óptimas en la captura del ángulo o el detalle deseado. Además, muchas veces no se puede acceder a los helicópteros, aunque siempre ha existido la posibilidad de alquilar un helicóptero, pero esto es costoso. Finalmente, la organización de la operación requiere de bastante tiempo, lo que va en contra de la prioridad de limpiar el sitio del accidente tan pronto como sea posible.
Las imágenes aéreas del sitio del accidente son útiles para los investigadores de accidentes aéreos, pues pueden capturar detalles de todo el sitio. Se pueden capturar desde el punto de impacto inicial hasta el lugar final en el que se encuentra la aeronave accidentada. Cuando se trata de una aeronave de gran envergadura, las imágenes pueden detallar las marcas de su trayectoria en tierra y documentar daños que no se perciben con las imágenes desde tierra. Con esto se puede identificar cómo la aeronave golpeó el suelo. Dichas tomas aéreas son útiles para mostrar las posiciones relativas de obstáculos como árboles o edificios, que pueden haber sido golpeados en el impacto. Por otra parte, ayudan a revelar el terreno circundante y el entorno al cual el piloto se enfrentó en el momento del accidente.

En este contexto, es posible implementar el uso de RPAS en el escenario de accidentes aéreos, lo cual facilita la recopilación de información. De esta manera, la herramienta tiene como función principal apoyar al investigador para encontrar las causas del accidente aéreo en el menor tiempo posible. Esta tarea se cumple gracias a la implementación de equipos aéreos con cámaras para capturar videos, fotos e imágenes multiespectrales y sobre las cuales el investigador tiene la plena potestad sobre la operación de los RPAS, los detalles de la escena y la calidad de la información obtenida. El término RPAS utilizado en la regulación civil de Colombia se considera similar al Sistema de Aeronave No Tripulada (UAS) y al término común dron o drone (Aerocivil, 2015) para este trabajo.

\section{Metodología}

Este trabajo tiene una orientación exploratoria, implementa una metodología analítica-descriptiva y toma como eje temático la integración de una nueva tecnología en un procedimiento claramente definido del tratamiento e intervención de la escena de un accidente aéreo. Los elementos constitutivos del análisis son (1) procedimientos para la investigación de accidentes 
aéreos, (2) operación de RPAS en entornos de investigación y (3) tipo de información que el RPAS puede obtener. El enfoque investigativo se encuentra en la intersección temática de cada elemento de análisis (figura 1).

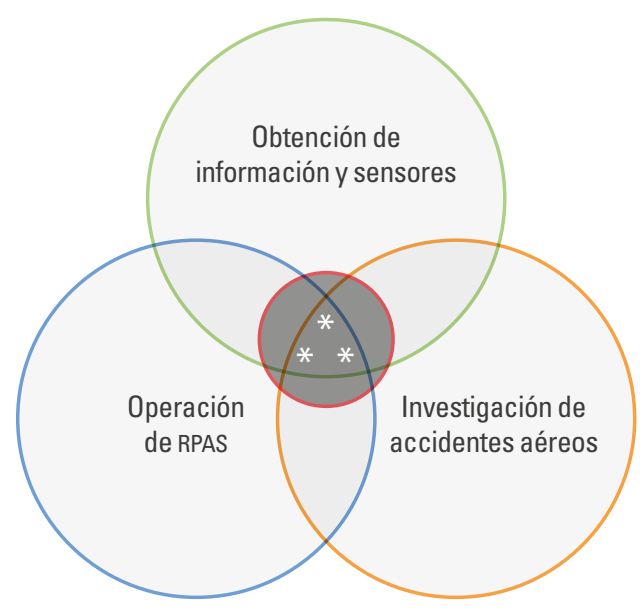

Figura 1. Diagrama del elemento de análisis Fuente: elaboración propia.

En referencia a los elementos constitutivos del análisis, la investigación de accidentes aéreos es una actividad profesional, con la que se deben aclarar las causas de un accidente utilizando herramientas y equipos tecnológicos definidos en sus directrices (OACI, 2015). Estos elementos se utilizan para obtener información clara, objetiva y veraz. La inclusión de nuevas herramientas y tecnologías de apoyo debe estar claramente reglamentada para que no haya ambigüedades o imprecisiones en los procedimientos. Los RPAS se componen de un sistema de enlace de datos entre la aeronave y la estación terrestre, los cuales deben ajustarse al entorno de trabajo de un investigador de accidentes aéreos. Los sistemas de enlace de datos y estaciones terrestres pueden ser estandarizados y simplificados en la escena. Los RPAS implementados deben ser apropiados para cada etapa de la investigación, dependiendo del tipo de información que se requiere obtener en cada una de ellas.

\section{Análisis para la implementación}

\author{
Procedimiento para la investigación \\ de accidentes aéreos
}

Para la investigación de accidentes aéreos, los procedimientos se establecen en el Manual de investigación de accidentes e incidentes de aviación (OACI, 2015). Este manual proporciona los datos necesarios para la investigación y el procedimiento para obtener pruebas y registros de los hallazgos en la escena del accidente. El Grupo de Investigación de Accidentes es la autoridad del Estado colombiano responsable de la investigación de los accidentes e incidentes aéreos de todos los eventos aéreos civiles que involucren una aeronave con matrícula de estado colombiana, ya sea que estos ocurran dentro o fuera de Colombia. Aunque el AIG es un organismo que depende de la Autoridad de Aviación Civil de Colombia (Aerocivil, 2016), tiene la autonomía para llevar a cabo investigaciones técnicas objetivas de accidentes e incidentes aéreos.

El objetivo del AIG es proporcionar el servicio de investigación sobre eventos aéreos para desarrollar una investigación técnica y objetiva, con el propósito de emitir recomendaciones de seguridad para evitar y prevenir eventos futuros en la industria aeronáutica. Su trabajo no tiene por objeto determinar la falta o responsabilidad de una organización o individuo de acuerdo con las regulaciones nacionales e internacionales (RAC 114, 2017; OACI, 2001).

La investigación de un accidente aéreo comienza en su escena tan pronto como sea posible y reúne un amplio espectro de experiencia técnica que es necesario para resolver complejos problemas de seguridad de transporte aéreo. Los miembros del equipo de reacción inmediata (Go Team) deben estar a disposición las veinticuatro horas del día, pues puede ser necesario que se desplacen a cualquier entorno del territorio nacional. Debido a que no hay manera de saber si la escena del accidente será en las montañas, valles o selvas, la mayoría de los miembros del Go Team no pueden tener una maleta completamente lista con la ropa 
adecuada para el terreno, pero sí pueden tener listas las herramientas útiles, como llaves cuidadosamente seleccionadas, destornilladores y dispositivos especiales. Todos los investigadores deben llevar linternas, grabadoras, cámaras, cinta y otras herramientas. En el futuro, teniendo en cuenta los resultados presentados en este documento, podrían incluirse RPAS a la lista.

Según el procedimiento establecido para investigar un accidente, se debe reconocer el área, identificar las vías de acceso, y después desarrollar las actividades del personal del equipo de búsqueda y rescate. Pueden implementarse RPAS para tomar fotografías aéreas y apoyar las actividades de ubicación o vigilancia. Posteriormente, comienza la investigación del accidente. Es necesario empezar por localizar y recuperar la documentación y la grabadora de datos de vuelo en la escena del accidente para mantenerla en custodia e investigar los hechos. Después de esta recuperación, se identifica la posición de los componentes de la aeronave por medio de fotografías que permitan determinar su ubicación y estado físico. Estas fotografías permiten analizar las condiciones de cada uno de los componentes para identificar grietas, fracturas, deformaciones, entre otras.

Después del análisis de los componentes, se realiza un trazado de la distribución de los restos. En esta actividad se puede usar un RPAS para simular y recrear la trayectoria de la aeronave antes del accidente así como su huella en tierra y su altitud en el momento del accidente. Por otro lado, se incluyen las declaraciones de los testigos que presenciaron el suceso. Toda esta información debe recopilarse en el informe final de la investigación (OACI, 2015).

\section{Tipo de información obtenida con RPAS}

LOS RPAS recopilan la información por medio de los sensores que poseen a bordo. Uno de los sensores más relevantes son las cámaras, que permiten obtener fotografías y videos desde múltiples puntos de vista y alta calidad de imagen. El tipo de información recopilada depende del procedimiento en el que se utilice el RPAS en la escena del accidente aéreo. Existen procedimientos normales y dentro de ellos se ha identificado que las siguientes tareas pueden implementarse factiblemente en una aeronave remotamen-

te pilotada:

a) Inspección de la escena.

b) Búsqueda de la aeronave accidentada.

c) Determinación de la altura de los objetos presentes en la escena.

d) Evaluación de seguridad de la escena del accidente.

e) Reconstrucción y visualización de la trayectoria del vuelo.

Los sensores y RPAS deben seleccionarse de acuerdo con la información que quiere obtener. Por ejemplo, en la toma de imágenes de precisión, un estudio de la Facultad de Geología de la Universidad de Patras establece que se puede implementar un RPAS con cámaras de acción en gimbal ${ }^{1}$. En esta configuración, las cámaras son capaces de capturar fotos a megapíxeles específicos, con longitud focal claramente definida y paso de píxeles en $\mu \mathrm{m}$ (Universidad de Patras, 2017). Además, el RPAS se equipa con un módulo de Sistema Satelital de Navegación Global (GNSS, por sus siglas en inglés) para lograr vuelos automáticos y con un doble sistema gimbal que le permite la captura simultánea de la misma escena en varios ángulos (por ejemplo, tomas verticales y oblicuas) con el fin de realizar diferentes vistas de la misma área (Universidad de Patras, 2017). Otro ejemplo es el uso de cámaras térmicas que ayudan a detectar incendios ocurridos en la escena del accidente y a determinar la línea de propagación del incendio. Así mismo, los sensores multiespectrales pueden llegar a tomar valores de seis bandas espectrales; se pueden seleccionar diferentes bandas mediante el uso de filtros. Debido a que estos sensores están diseñados para el estudio de parámetros relacionados con la reflexión de luz visible y no visible, sirven para diferenciar la vegetación y otros elementos en la escena de un accidente, como fluidos, capas

1 Los gimbal son soportes con suspensión cardán que controlan y estabilizan el movimiento de la cámara. 
vegetales removidas y materiales metálicos. Las bandas son seleccionadas en las gamas de verde, rojo e infrarrojo cercano. Según la banda, los elementos de la superficie presentan diferentes respuestas de absorbancia y reflectancia (Díaz, 2015).

En un RPAS, la georreferenciación mediante GPS es útil, pues ayuda a controlar la precisión de las imágenes. La precisión se determina en referencia al desplazamiento de una imagen con respecto a la siguiente tomada por el RPAS en movimiento. De este modo se pueden indicar los errores en la georreferenciación y en el área (Universidad de Patras, 2017). La suma de todas las imágenes tomadas en una misma área y con relación de desplazamiento, se define como mosaico. Por otro lado, la longitud focal de la cámara determina la precisión de las imágenes que se deseen utilizar en el RPAS. Para ello debe buscarse una escala adecuada; por ejemplo, si la cámara tiene una distancia focal corta, la fotografía aérea se ve afectada por factores como las nubes. Resultados de otras investigaciones indican que la precisión de la escala supera el 99,7 \% y que la corrección de exactitud de la georreferenciación alcanza el 99,8 \% (Universidad de Patras, 2017). Por lo tanto, el uso de imágenes tomadas con RPAS es una solución viable para la cartografía de alta precisión en las tareas de investigación de accidentes aéreos. Este proceso de tratamiento de mosaicos de imágenes aéreas se conoce como fotogrametría (Sánchez, 2007).

El propósito de la fotogrametría es describir la geometría de una escena con alta precisión, presentando las unidades en un marco absoluto. Esto es esencial para complementar la metrología de la escena. Un método convencional utilizado para aumentar la precisión metrológica en la fotogrametría aérea es tener puntos cuyas coordenadas se miden por topografía. Esos puntos se utilizan para convertir capturas relativas al sistema absoluto. Esta técnica es eficaz, pero las condiciones de la escena pueden limitar el procedimiento (por ejemplo, si la escena es inaccesible o insegura). La fotogrametría con RPAS georreferenciada con puntos de control, alcanza una exactitud absoluta típica de 1 a $5 \mathrm{~cm}$ (Santos, 2014). La fotogrametría puede realizarse con o sin puntos de control.

\section{Inspección de la escena}

Con la inspección de la escena del accidente aéreo se busca determinar las condiciones del lugar y delimitar la escena. Un RPAS puede ser usado para el levantamiento de información; es decir, para obtener imágenes y videos básicos con información preliminar fácil de interpretar. Esta información se puede obtener mediante transmisión en tiempo real al investigador desde diferentes perspectivas; no se requiere del acceso directo del investigador a la escena, lo cual reduce significativamente las posibilidades verse contaminada. Al delimitar la escena es posible realizar tomas fotogramétricas que se procesan con software especializados de fácil acceso; con estas tomas se obtienen mapas completos de la escena.

LOS RPAS se utilizan para determinar otros datos de la inspección; por ejemplo, para identificar ramas de los árboles que se rompen cuando la aeronave trata de aterrizar, para determinar la actitud de impacto de la aeronave a través de los mapas o para tomar fotografías detalladas de las evidencias distantes al suelo. Con los mapas y los demás detalles se construyen planos del accidente. Estos planos, cuando son tomados con helicóptero alteran la escena debido al downwash, que afecta a los árboles. Un RPAS es particularmente útil, cuando la aeronave necesita ser despejada rápidamente, para documentar escombros y marcas en una pista.

\section{Búsqueda de la aeronave accidentada}

En la búsqueda de la aeronave accidentada se pretende hallar el lugar en el que se encuentra la mayor parte de los componentes y de cualquier otro resto aislado de la aeronave, así como evidencias del impacto. Con las cámaras de un RPAS es posible encontrar objetos más pequeños mediante video de alta resolución en vivo. Estos videos e imágenes pueden albergarse en la memoria del equipo para que la información esté disponible después del vuelo y pueda ser analizada. De este modo se pueden realizar nuevas búsquedas detalladas que proporcionen información complementaria 
en la investigación. Debido a que se cuenta con la posición georreferenciada del RPAS, se puede obtener una ubicación más precisa del objeto con el parámetro leído en una estación terrena. Algunos RPAs tienen sistemas de posicionamiento RTK (por sus siglas en inglés, Real Time Kinematic). Está tecnología se basa en dos GPS, uno es el GPS móvil en el RPAS y el otro es un GPS fijo en la estación terrena. El sistema RTK soluciona la dispersión de la posición GPS, logrando así precisiones de centímetros (Villarroel et al., 2014). Esto es particularmente útil para escanear la escena y localizar marcas que son difíciles de identificar desde el suelo.

Otra tecnología utilizada para el estudio de áreas es la tecnología LIDAR (por las siglas en inglés para Detección de Imágenes Láser y su Rango). Esta se utiliza como fuente de información geográfica con niveles de detalle superiores a los de las demás tecnologías operativas. Esta tecnología permite obtener puntos georreferenciados de todos los elementos de la superficie de la tierra que son ajustados en el espacio gracias a los GNSS que se acoplan con el sensor en el RPAS y con estaciones de control en tierra (Martínez Tobón et al., 2013). Además, los RPAS con sensores hiperespectrales capturan información en intervalos de $400 \mathrm{~nm}$ y hasta $1000 \mathrm{~nm}$. De esta manera toman datos hasta de 300 bandas, con los que logran la máxima información espectral (Díaz, 2015). Esta información ayuda a determinar los elementos presentes en la escena del accidente aéreo que por alguna condición del terreno no se pueden identificar fácilmente de manera visual (Salamanca Céspedes \& Pérez Castillo, 2008); por ejemplo, fluidos y otros componentes de la aeronave.

\section{Altura de los objetos presentes en la escena}

El RPAS proporciona una lectura rápida de la altura que se muestra en el dispositivo de telemetría. Esta información ayuda a determinar la medida vertical de obstáculos o de evidencias del impacto en la escena (tales como edificios, árboles, entre otros) debido a que se puede volar el RPAS al nivel de la parte superior de estos objetos. Además, es posible tomar fotografías de los detalles de estos objetos sin afectar considerablemente la escena, pues el downwash de los rotores del
RPAS no es significativo si se lo compara con el de un helicóptero (Flight Safety Foundation, 2017). La altura del punto de despegue se calcula utilizando tanto el GPS y el sensor barométrico interno del RPAS, como sensores láser o ultrasónicos. Estos últimos son comercialmente implementados en aeronaves desarrolladas a base de tarjetas centrales derivadas de arduino que usan ultrasonido, y en aeronaves de ala fija de fabricación francesa que usan láser sin generar consumos de batería significativos.

\section{Evaluaciones de seguridad de la escena del accidente}

Los accidentes pueden representar riesgos físicos para los investigadores cuando hay componentes peligrosos, como químicos, combustibles, artillería a bordo, o cuando las condiciones orográficas son difíciles, como en las faldas de acantilados, entre otras. El RPAS puede utilizarse para volar cerca de los restos e identificar así su ubicación y estado. Esto proporciona información al equipo investigador $o$ al de búsqueda y rescate, quienes se encuentran en una posición segura, con lo que se evita poner en riesgo al personal humano.

\section{Reconstrucción y visualización de la trayectoria de vuelo}

El RPAS ofrece un método de bajo costo para la obtención de información desde el punto de vista del piloto. La logística de carga de la aeronave puede reducirse a transportar el RPAS en un morral de espalda y a transportar sus baterías, que no superan los $500 \mathrm{~g}$ (en ocasiones, este peso incluye la aeronave con todos sus sensores). En el lugar del accidente, el RPAS puede ser armado y despegado en corto tiempo. El gasto y la logística que requiere operar un helicóptero, para recrear una trayectoria final estimada de la aeronave con el fin de reconstruir los sucesos previos al impacto, son mucho mayores. Por ejemplo, si la aeronave se estrelló por causa de una pérdida de potencia, entonces un video de la trayectoria final permite identificar las opciones que tuvo el piloto para realizar una maniobra de emergencia; o, si la aeronave golpeó un obstáculo, la 
vista del RPAS permite revelar lo sobresaliente que era el obstáculo. Esta vista se puede obtener en diferentes momentos del día y en diferentes condiciones de iluminación (Airgomedia.com, 2017), puesto que la operación del RPAS en cualquier momento es fácil y rápida.

\section{Tipos de RPAS}

Para las tareas que realiza un investigador con diferentes tipos de sensores, se deben evaluar las condiciones operativas del RPAS teniendo en cuenta sus características de rendimiento ${ }^{2}$. Actualmente, los RPAS fabricados tienen varias similitudes con las aeronaves tripuladas. Se pueden encontrar RPAS cuya configuración y operación se basa en aeronaves de ala fija, de tipo avión, y ala volante; ala rotatoria como helicóptero, y multirotor. Esta última configuración es la más común y los RPAS se clasifican de acuerdo con el número de rotores y su ubicación. Los siguientes son ejemplos de configuración multirotor: configuración $\mathrm{x}$, en la que ningún rotor está en el eje longitudinal, de tal manera que se forma una $x$ con el número de rotores; la configuración $\mathrm{T}$, en la que el eje longitudinal coincide con un motor delantero, y la configuración y para multirrotores con brazos impares. LoS RPAS multirotor tienen más de dos rotores (tres, cuatro, seis u ocho). Dependiendo del tipo de configuración de RPAS, el equipo puede ofrecer diferentes ventajas operativas. Los equipos multirotor son más prácticos para áreas confinadas y capturas estáticas por sus características de vuelo estacionario. Los RPAS de ala fija son ideales para vuelos más largos, grandes coberturas aéreas y un largo recorrido de rutas. LoS RPAS tienen una capacidad de carga que limita el peso máximo de despegue, dicho peso se denomina "carga paga". El peso máximo de despegue está directamente relacionado con la autonomía de vuelo (tiempo total de vuelo) de una aeronave.

Como parte del proceso de análisis, se hizo una búsqueda de información relativa a los RPAS que se encuentran en el mercado. Aplicando el método de análisis de performance de aeronaves de Jan Roskam (2003), fue posible identificar tres segmentos de peso3: menores a 2,5 kg, entre 2,5 y $12 \mathrm{~kg}$ y mayores a $12,5 \mathrm{~kg}$. En la figura 2, se presenta la relación entre peso y autonomía de RPAS comerciales, con pesos inferiores a $2,5 \mathrm{~kg}$ y autonomía inferior a 16 minutos. Esta figura muestra una dispersión grande entre modelos.

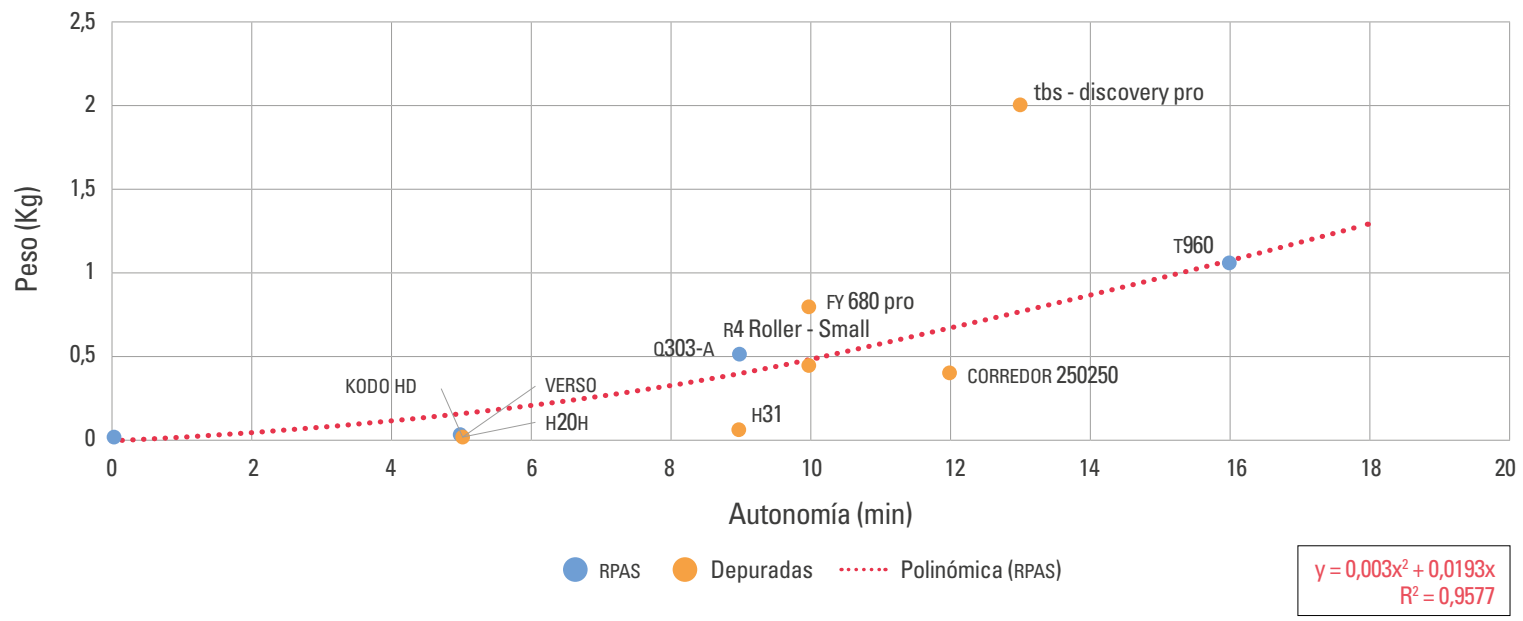

Figura 2. Rendimiento de RPAS (menos de $2,5 \mathrm{~kg}$ y $16 \mathrm{~min}$ )

Fuente: elaboración propia.

2 Es decir, el performace de cada tipo aeronave.

3 Entre los cerca de ochenta y cinco modelos de RPAS comerciales analizados. 
La figura 3 muestra una tendencia de autonomía de RPAS comerciales con pesos entre $2,5 \mathrm{~kg}$ y $12 \mathrm{~kg}$ y una autonomía inferior a 250 minutos. En este segmento se encuentra la gran mayoría de RPAS con sensores destacados para actividades multipropósito. Estos RPAS tienden a tener un diseño portable y unas técnicas de armado y operación simples. Además, en este rango de pesos se encuentra la mayor cantidad de oferta en el mercado y la mayor cantidad de unidades producidas por modelo. Estos datos muestran una tendencia polinómica de $6{ }^{\text {to }}$ grado, lo cual sugiere un crecimiento de la oferta de modelos dentro de ese mismo rango de peso. Además, se resalta la gran dispersión de los modelos en términos de autonomía, lo cual fortalece la hipótesis de que los RPAS presentan múltiples ventajas operativas y rangos de autonomía cada vez mayor (Gómez et al., 2017).

Adicionalmente, la figura 4 muestra una tendencia en la autonomía de RPAS encontrados en el mercado con pesos superiores a $12 \mathrm{~kg}$. Se puede apreciar una primera tendencia superior de baja autonomía y alto peso, que caracteriza a los RPAS utilizados para aplicaciones muy especializadas, que requieren de equipos de uso avanzado y tecnología robusta. Usualmente, esos equipos requieren de una infraestructura mayor para su operación. Se observa además una tendencia natural de aumento de la autonomía en cuanto el peso se reduce. Esto sugiere un desarrollo industrial con tendencia a la permanencia de esta tecnología, cada vez más precisa, para tareas especiales.

El análisis anterior determina que la mayoría de RPAS comerciales tienen pesos entre $2,5 \mathrm{~kg}$ y $12 \mathrm{~kg}$. También se utilizan RPAS de más de $12 \mathrm{~kg}$ para cargar un equipo especial de alto rendimiento. Además, se encontró que las aeronaves cuya autonomía es superior a la de las demás, tienen una configuración de motor de combustión, a diferencia de las otras, que tienen una configuración de plantas motrices eléctricas. Este análisis de rendimiento puede permitir al AIG seleccionar equipos que se ajusten a sus necesidades operativas en el desarrollo de la investigación.

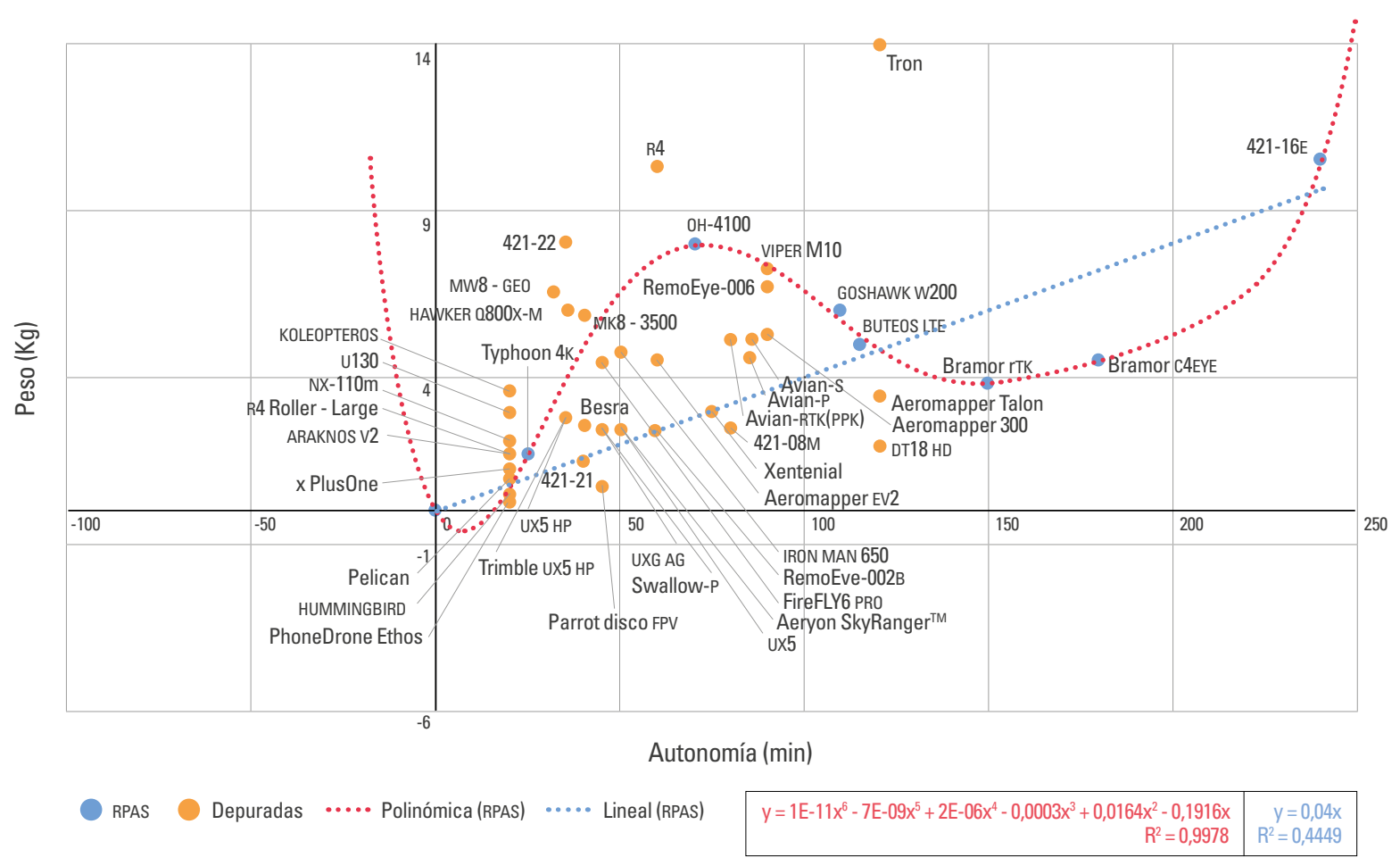

Figura 3. Rendimiento de RPAS (desde 2,5 kg hasta $12 \mathrm{~kg}$ ) para una autonomía máxima de 250 min

Fuente: elaboración propia. 


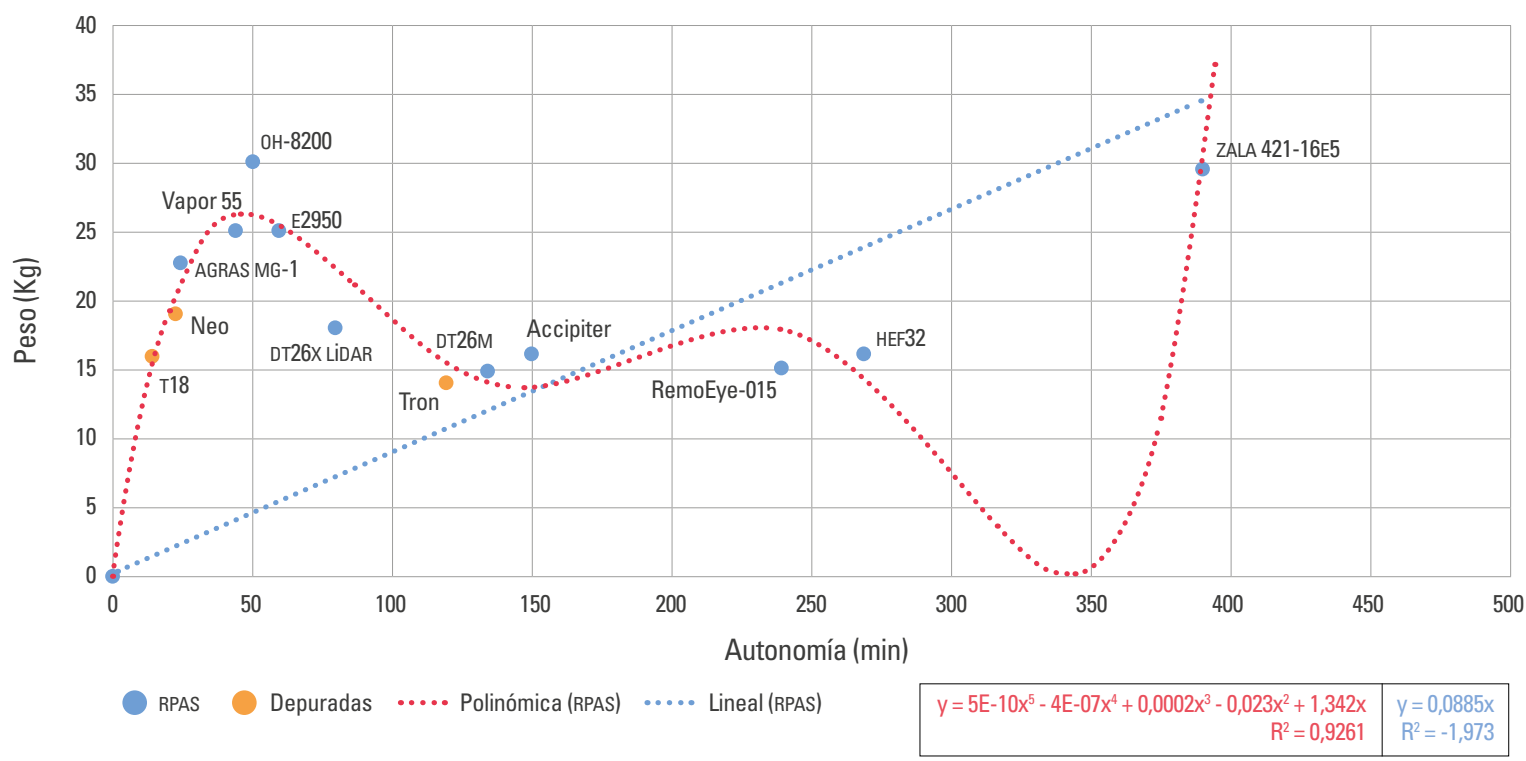

Figura 4. Rendimiento de RPAS de más de $12 \mathrm{~kg}$

Fuente: elaboración propia.

\section{Beneficios del software de fotogrametría para el procesamiento de imágenes de un accidente}

Las imágenes aéreas de la escena de un accidente de aviación pueden ser procesadas con diferentes herramientas de software de fotogrametría disponibles comercialmente (Martorell, s.f.)1. Este procesamiento trae una serie de beneficios, como el desarrollo de ortomosaicos y modelos tridimensionales 3D del terreno. El ortomosaico es también una herramienta útil para sitios de accidentes que abarcan grandes extensiones de terreno, pues permite unificar múltiples imágenes en una única gran imagen con las características de resolución de cada imagen componente. Esto permite analizar con mayor detenimiento la escena durante el estudio del accidente en la oficina del investigador, lo que abre la posibilidad de hallar evidencia que posiblemente no fue encontrada en el momento de la primera intervención y levantamiento. Por otro lado, un ortomosaico es un mapa y puede ser utilizado para planear la recuperación de los restos en escenas de accidentes que abarcan grandes extensiones de terreno. Así mismo, el software facilita obtener las mediciones de altura de curvas de nivel en el terreno. En el mercado de software de fotogrametría se pueden encontrar diferentes soluciones que ofrecen diferentes características comerciales. Algunos de estos programas, de uso libre e ilimitado, vienen incluidos con compra del RPAS. Estos pueden llegar a procesar modelos de alta calidad y extensiones. Los niveles de calidad de la información dependerán, en general, de la altura de vuelo, el porcentaje de solapamiento de las imágenes, las características de la cámara y la técnica de procesamiento. Los tiempos y costos computacionales dependerán del equipo de cómputo y del software. La mayoría de los software ofrecen varias alternativas de procesamiento en la nube, con respuesta aproximada de resultados a las 24 horas.

El modelo 3D (figura 5) es muy útil para dar información a las personas que no han asistido al lugar del accidente. Con este modelo se puede interactuar acercando, alejando y rotando para mostrar todas las marcas de tierra y la distribución de los daños. En comparación con una serie de imágenes fijas (Serna, 2015), este modelo hace más fácil que las personas visualicen la escena del accidente. Los modelos 3D recrean entornos animados que pueden ser vistos por personas que no poseen el software. Además, si ha transcurrido un 
tiempo entre el levantamiento de información del accidente y la redacción del informe, el modelo 3D permite refrescar la información. Sin embargo, hay límites para el modelo 3D. Este puede contener elementos que no son tan detallados como las imágenes iniciales utilizadas para crearlo, por lo que es un apoyo y no debe ser visto como un reemplazo de las imágenes sin procesar.

Es útil generar la mayor cantidad de productos que se pueda con el software, pues, por ejemplo, se ha identificado que en algunos casos la imagen ortomosaica de una escena del accidente es más útil que un modelo 3D (PIX4D, 2016). El modelo sirve efectivamente como una reconstrucción de la escena del accidente muy detallada y requiere de menor tiempo en comparación con el dibujo de un boceto del sitio. Si el investigador toma nota de los objetos, que es poco probable que se vean en las imágenes aéreas, puede confiar en el ortomosaico para documentar las posiciones de las partes principales de la aeronave y sus posiciones relativas a las marcas en tierra. Siempre ha resultado difícil dibujar una trama de los daños a escala, pero el ortomosaico permite realizar esta labor. Por ello, el investigador puede cargar un ordenador portátil para comprobar la calidad del ortomosaico antes de tomar decisiones. Es muy importante hacer algunas mediciones manuales, usando una cinta métrica o un medidor láser, entre puntos que serán identificables en las imágenes, ya que esto permite comprobar la exactitud del modelo y del ortomosaico. Adicionalmente, estas medidas se pueden introducir en el software de fotogrametría usando la opción "Escala", la cual reoptimiza el proyecto usando las distancias conocidas para reducir el margen de error (Vázquez-Tarrío, 2017).

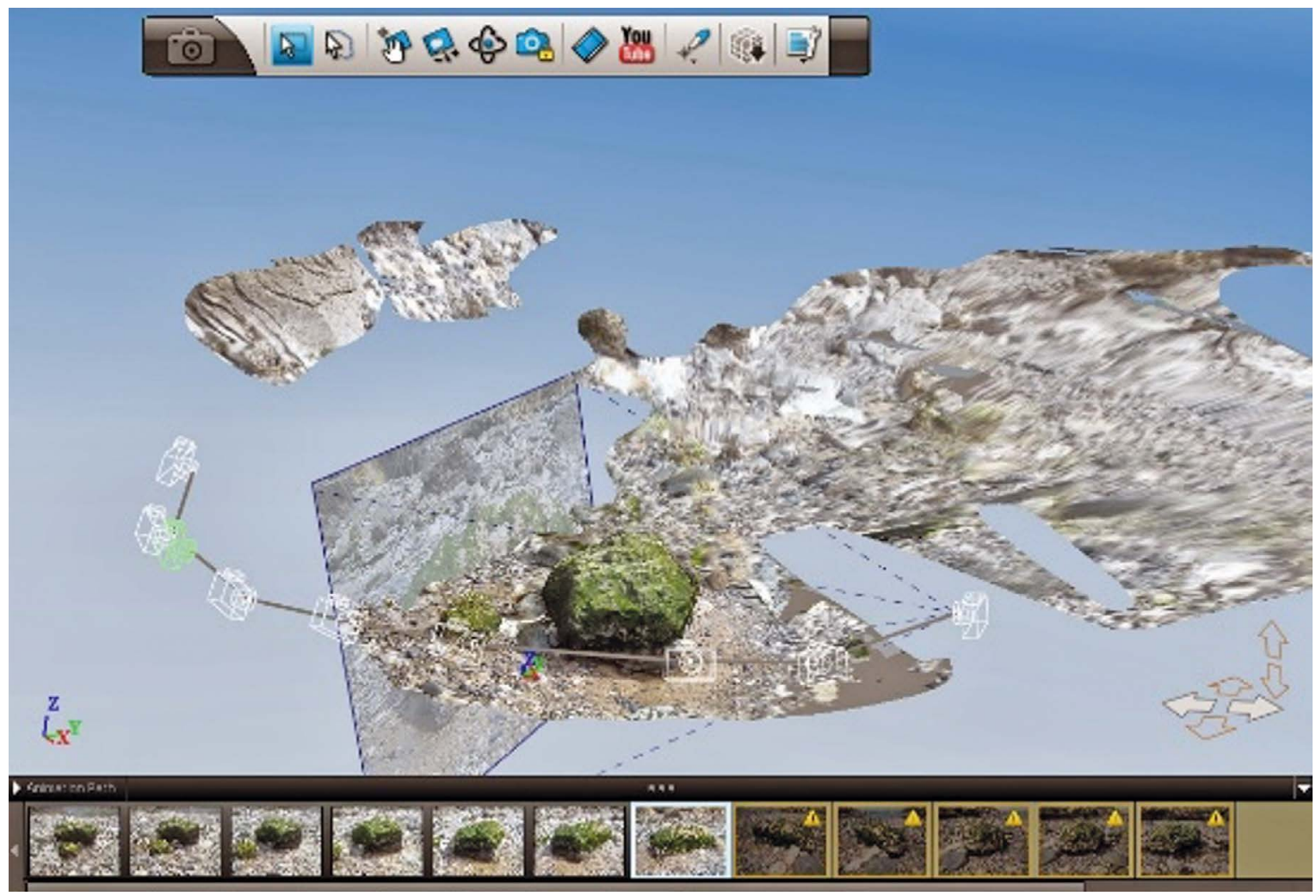

Figura 5. Levantamiento en tres dimensiones

Fuente: tomado de http:/intergalacticrobot.blogspot.com.co/2014/03/ 


\section{Regulación de RPAS}

La regulación para cualquier práctica aérea en el mundo debe estar ceñida a las directrices de la Organización de Aviación Civil Internacional (OACI, s.f.). Sin embargo, esta organización no tiene procedimientos establecidos para la operación de RPAS en contextos estatales. Aun así, se considera que, debido a que varios países de la región latinoamericana están usando RPAS y desarrollando marcos regulatorios, la región debe adoptar un enfoque cooperativo para el desarrollo de la reglamentación. La OACI sugiere elementos generales para evaluar la clasificación de RPAS (Parra, 2017). No obstante, para fines específicos como el de investigar accidentes aéreos o similares, no se han definido límites claros. La Aerocivil ha avanzado en un modelo para orientar la operación de RPAS en aplicaciones comerciales, compilado inicialmente en la norma CR-5100-082-002 (Aerocivil, 2015). Esta norma fue reemplazada por la resolución 04201 del 27 de diciembre del 2018, en la cual se encuentran las indicaciones de operación de los RPAS, establecidas como anexo 13 del RAC 91 (Aerocivil, 2018).

En Colombia, los RPAS que no cumplen con los requisitos de la 04201 no están autorizados para operaciones de aviación civil (Romero \& Gomez, 2017). La reglamentación sugiere que el RPAS debe utilizarse de manera que exista el menor riesgo para la integridad de las personas, las propiedades u otras aeronaves, de acuerdo con las condiciones del permiso otorgado según el tipo de operación. Esta es la filosofía central del sistema de SMS y el propósito de la Aerocivil. El funcionamiento del RPAS estará limitado a operar exclusivamente durante el día y en condiciones meteorológicas visuales (vMc, por sus siglas en inglés). Por otra parte, una persona no podrá operar un RPAS en Colombia sin cumplir con las condiciones de aeronavegabilidad y las habilidades técnicas establecidas. Además, se requiere de información del operador de RPAS, sistema de certificación para sus pilotos y su inclusión en la base de datos de RPAS de la Secretaría de Seguridad Operacional y de la Aviación Civil (Aerocivil, 2018).

Dado que un RPAS tiene la capacidad de maniobrar en vuelo, mantenerse, moverse en el aire, y transportar cargas, debe cumplir con las condiciones establecidas en las definiciones de «Aeronaves» contenidas en el artículo 1789 del Código de Comercio de Colombia, en el RAC 1 (Aeronáutica Civil de Colombia, 2015) y en los anexos técnicos de la OACI. LOS RPAS son aeronaves que se encuentran en el mercado para múltiples propósitos, como vuelos FPV, automáticos, para fotogrametría o similares; asistidos, para maniobras de reproducción de posibles trayectorias de la aeronave accidentada, y demás propósitos citados al principio del documento. Por lo tanto, los RPAS estarán sujetos a las condiciones técnicas determinadas por la autoridad de aviación civil. Se debe aclarar que estas normas son aplicadas para RPAS civiles comerciales. El uso de RPAS para la investigación de accidentes aéreos se clasificaría como aviación de Estado. Este tipo de aviación tiene sus directrices internas, similares en materia de seguridad a las de la aviación civil comercial, pero no se regula por las mismas normas de esta (Aeronáutica Civil de Colombia, 2015).

\section{Propuesta para el uso de RPAS en investigaciones de accidentes aéreos}

Para usar un RPAS en el proceso de investigación de un accidente aéreo, se requiere que las tareas antes mencionadas estén articuladas con las actividades que se encuentran descritas en el Manual de investigación de accidentes e incidentes de aviación (OACI, 2015).

Para la toma de muestras pictográficas de la escena del accidente aéreo, se identificaron las actividades que deben ser realizadas con respecto a la toma de fotografías y evidencias gráficas de la escena del accidente. En el Manual de investigaciones de accidentes aéreos, parte II, de la OACI (2015), se contemplan actividades por parte del grupo de fotografía. Estas actividades están descritas en el apéndice 2 del documento, el cual asigna al grupo de fotografía cuatro actividades específicas a desarrollar:

1. Actividad 16 - Fotografía del sitio (fase 1 )

2. Actividad 30 - Fotografía del sitio (fase 2 )

3. Actividad 63 - Análisis e informe del grupo fotografía/video

4. Actividad 65 - Análisis técnico y conclusiones 
No obstante, el grupo fotografía/vídeo debe realizar tareas de actividades asignadas a otros grupos, como la toma de muestras de pictografías, según las necesidades específicas de las actividades que los investigadores realizarán. Por lo tanto, en el momento de tomar una fotografía, se debe tener en cuenta la nitidez de la imagen, además de tener una referencia escalar y una buena iluminación (que permite identificar su composición). De acuerdo con esto, para la toma de fotografías se deben tener en cuenta tres categorías:

\section{Fotografía general}

Según los estándares de procedimiento del manual Investigación de accidentes e incidentes de aviación (RAC 114,2017 ) (basado en el manual de la OACI, 2015) y que contiene condiciones similares a la FAA (Federal Aviation Administration) se mencionan ocho fotos de la aeronave para la fotografía de accidentes aéreos, las cuales rotan cada 45 grados alrededor de la aeronave para una vista desde techo (siempre que la aeronave se encuentre completa en un mismo punto). En la figura 6 (b) se muestra, por medio de puntos, la toma clásica de imágenes. En comparación, se puede ver la imagen aérea básica con un RPAS en la figura 6 (a).

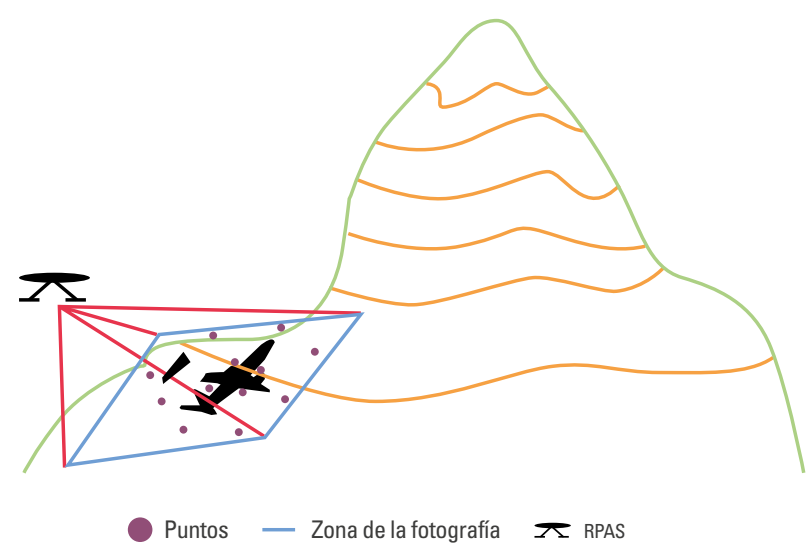

(a)

\section{Fotografía particular}

Según los estándares de procedimientos para la fotografía en investigación de accidentes aéreos, se requieren cuatro fotos tomadas en las uniones ala-fuselaje para las zonas del borde de ataque y borde de fuga.

\section{Fotografía detallada}

Si el investigador detecta otra zona de la aeronave accidentada, se recomienda un ángulo de visión menor a 60 grados que permita enfocar la falla, golpe, fisura o las imperfecciones en la aeronave accidentada (Martín, 2008). Esta tarea puede ser apoyada con RPAS gracias a su autonomía, que normalmente está entre 15 y 25 minutos para RPAS de entre 2 y 12 kilogramos, de tipo multirotor, de fácil portabilidad y operación. Además, dicho RPAS puede ser usado en un área transitada o en áreas rurales, lo que facilita la obtención de imágenes y videos desde ángulos óptimos. Del mismo modo, las tomas pictográficas de la zona ayudan a identificar los elementos ya analizados. Por esta razón, un RPAS es capaz de reconocer el área e identificar las vías de acceso con menor riesgo para asegurar un acceso rápido a un área específica (figura 7).

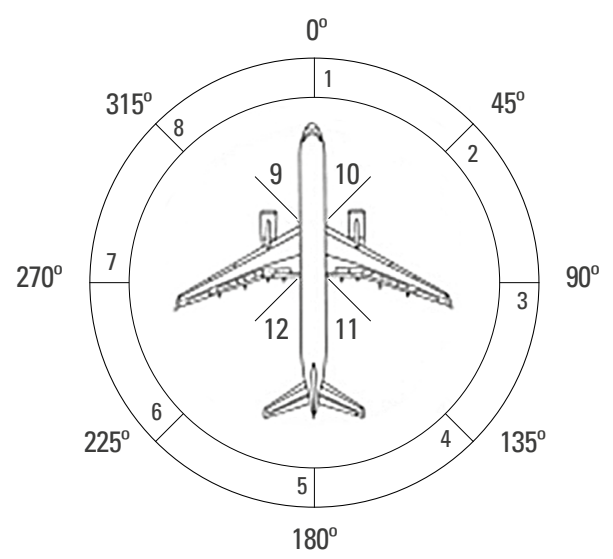

(b)

Figura 6. Esquema de fotografía con RPAS a y b

Fuente: elaboración propia. 


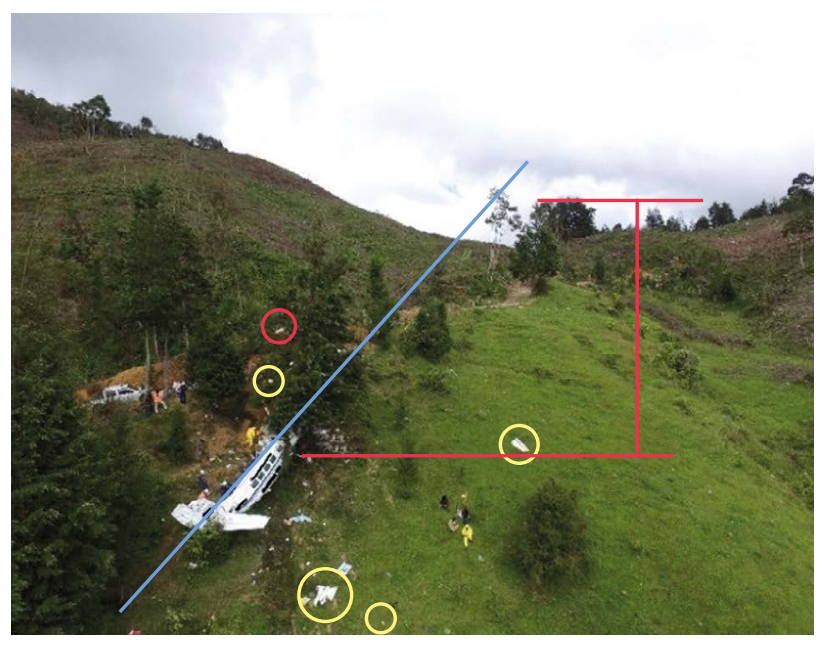

Figura 7. Ejemplo de una fotografía con RPAS en un accidente aéreo Fuente: elaboración propia.

\section{Conclusiones}

El RPAS permite la identificación de zonas específicas de accidentes. En esta identificación se debe dar prioridad a la identificación de los supervivientes y de posibles riesgos. El RPAS es capaz de tomar fotografías aéreas para identificar la distribución de las partes en el área del accidente. Además, tiene la capacidad de cubrir una gran área para tomar una fotografía a gran altitud, o realizar fotogrametría. Un RPAS es útil para la toma de imágenes y video, la inspección del sitio del accidente, la realización de la reconstrucción y visualizaciones finales de la trayectoria de vuelo. Un video en vivo de un RPAS puede ser usado también para buscar restos. Finalmente, el RPAS se puede desplegar en un tiempo corto en el sitio del accidente, y por lo tanto es capaz de documentar la escena sin ser afectado por las actividades de investigación y recuperación.

El software de fotogrametría se puede utilizar para crear mapas georreferenciados, imágenes ortomosaicas y modelos 3D de la escena del accidente. El modelo 3D es muy útil para informar a las personas que no han asistido a la escena del accidente con el fin de que tengan una clara idea de la escena al escribir el informe. El software permite tomar mediciones (hasta de un centímetro de precisión) de un sitio. Esto significa una disminución en el tiempo en la escena del accidente, en comparación con las mediciones manuales y el dibujo de bocetos.

La información presentada en este artículo ofrece el análisis teórico inicial de un proyecto de investigación en el que se busca definir el procedimiento estandarizado que debería ser consignado en un $\mathrm{Ma-}$ nual de investigaciones de accidentes aéreos. Se espera que este manual le sirva a la autoridad en materia de investigación de accidentes de cualquier Estado para que los RPAS se puedan utilizar de manera similar en la recolección de información en la escena de un accidente aéreo. De esta manera, se garantizará la calidad y la utilidad de los datos tomados con estas importantes herramientas. Además, se ampliará el espectro de información que un investigador de accidentes aéreos puede recopilar con los procedimientos convencionales.

En la segunda etapa del proyecto, se espera validar la propuesta de este manual, primero, con pruebas en campo, en un escenario controlado que simule un accidente de aviación, y luego en la escena real de un accidente. De este modo, se ajustará la propuesta inicial para que la autoridad aeronáutica ponga en funcionamiento el resultado de esta investigación.

\section{Referencias bibliográficas}

Aerocivil. (2016, 13 de septiembre). Investigación de accidentes e incidentes graves. http://www.aerocivil.gov.co/auto ridad-de-la-aviacion-civil/investigacion-de-accidentese-incidentes-graves

Aerocivil. (2018). Resolución 04201. Por la cual incorporan a la norma RAC91 de los Reglamentos Aeronáuticos de Colombia unas disposiciones sobre operación de sistemas de aeronaves no tripuladas UAS y se numeran como Apéndice 13, y se adoptan otras disposiciones. Unidad Administrativa Especial de Aeronáutica Civil.

Aeronáutica Civil de Colombia. (2015). Reglamento Aeronáutico de Colombia. Aeronáutica Civil de Colombia.

Airgomedia.com. (2017, 20 de enero). Northwestern presenta un currículo de drones para investigaciones y reconstrucciones de accidentes de tránsito. https://www.airgome dia.com/2017/01/20/deciding-on-a-drone/ 
Bell, P. L. (2012). Colombia: manual Comercial e Industrial. Banco de la República.

Díaz, J. J. (2015). Estudio de Índices de vegetación a partir de imágenes aéreas tomadas desde UAS/RPAS y aplicaciones de estos a la agricultura de precisión [Tesis de Maestría no publicada]. Universidad Complutense de Madrid.

Flight Safety Foundation. (2017, 22 de junio). U.K. AAIB Lauds Use of Drones in Accident Investigations. https://flightsafety. org/u-k-aaib-lauds-use-drones-accident-investigations/

Gómez, L., Parra, J., Vélez, J., Avellaneda, J., \& Ospina, L. (2017). Proposal to Use UAS in the Investigation of Aviation Accidents in Colombia. IEEE/AIAA 36th Digital Avionics Systems Conference (DASC), 1-6. https://doi.org/10.1109/ DASC.2017.8102149

Martín, J. R. (2008). Curso de fotogrametría digital. Universidad Politécnica de Madrid.

Martínez Tobón, C. D., Aunta Duarte, J. E., \& Valero Fandiño, J. A. (2013). Aplicación de datos LidAR en la estimación del volumen forestal en el parque metropolitano bosque San Carlos. Ciencia E Ingeniería Neogranadina, 23(1), 7-21. https://doi.org/10.18359/rcin.229

Martorell, A. (s.f.). Comparativa de programas para fotogrametría. https://geoinnova.org/blog-territorio/compara tiva-de-programas-para-fotogrametria/

Organización de Aviación Civil Internacional (OACI). (s.f.). Sobre la OACI. https://www.icao.int/about-icao/Pages/ES/ default_ES.aspx

Organización de Aviación Civil Internacional (OACI). (2001). Anexo 13. Investigacion de accidentes e incidentes de aviación. OACI.

Organización de Aviación Civil Internacional (OACI). (2015). Manual de investigación de accidentes e incidentes de aviación. OACI.

Parra, J. E. (2017, 3 de mayo). Tendencia dron en Colombia. Centro de Estudios Aeronáuticos. http://www.aerocivil. gov.co/cea/panacea/Pages/Tendencia-drone-en-Colo mbia.aspx
Pix4D. (2016, 28 de diciembre). Drones fly over aircraft accident scenes in UK: mapping wrecks, not causing them. Medium. https://medium.com/@Pix4D/drones-fly-over-aircraftaccident-scenes-in-uk-mapping-wrecks-not-causingthem-8c01171ffe53

RAC 114. (2017). Investigación de accidentes e incidentes de aviación. Unidad Administrativa Especial de Aronáutica Civil.

Roskam, J. (2003). Airplane Design. The University of Kansas.

Romero, J., \& Gomez, L. (2017). Proposal for RPAs integration into non-segregated airspaces. 2017 Integrated Communications, Navigation and Surveillance Conference (ICNS), Herndon, VA, 1-10.

Salamanca Céspedes, J. E., \& Pérez Castillo, J. N. (2008). LidAR, una tecnología de última generación, para planeación y desarrollo urbano. Ingeniería, 13(1), 67-76. https://doi. org/10.14483/23448393.2090

Sánchez, J. A. (2007) Introducción a la fotogrametría. UNSJ.

Santos, D. (2014). Fotogrametría usando plataforma aérea UAV. Universidad Politécnica de Cataluña

Serna, M. (2015). Uso de aeronaves no tripuladas (RPAS) en la conservación preventiva de la propiedad cultural [Proyecto de grado no publicado]. Universidad Politécnica de Valencia.

Universidad de Patras. (2017). UAV vs fotogrametría aérea clásica para estudios arqueológicos. Patras.

Vázquez-Tarrío, D., Borgniet, L., Liébault, F., \& Recking,A. (2017). Using UAS optical imagery and SfM photogrammetry to characterize the surface grain size of gravel bars in a braided river (Vénéon River, French Alps). Geomorphology, 285, 94-105. https://doi.org/10.1016/j.geomorph. 2017.01.039

Villarroel, D. D., Scaramuzza, F. M., Méndez, A. A., \& Vélez, J. P. (2014). El posicionamiento satelital y sus sistemas de corrección. Curso Internacional de Agricultura de Precisión, 13, 175-182. https://inta.gob.ar/sites/default/files/ script-tmp-inta_c3-_el_posicionamiento_satelital_y_ sus_sistemas_.pdf 